\title{
Low loss mid-IR transmission bands using silica hollow-core anisotropic anti-resonant fibers
}

Habib, Selim; Bang, Ole; Bache, Morten

Published in:

Proceedings of 2016 41st International Conference on Infrared, Millimeter, and Terahertz waves

Link to article, DOI:

10.1109/IRMMW-THz.2016.7758674

Publication date:

2016

Document Version

Peer reviewed version

Link back to DTU Orbit

Citation (APA):

Habib, S., Bang, O., \& Bache, M. (2016). Low loss mid-IR transmission bands using silica hollow-core anisotropic anti-resonant fibers. In Proceedings of 2016 41st International Conference on Infrared, Millimeter, and Terahertz waves (pp. 1-2). IEEE. International Conference on Infrared, Millimeter and Terahertz Waves https://doi.org/10.1109/IRMMW-THz.2016.7758674

\section{General rights}

Copyright and moral rights for the publications made accessible in the public portal are retained by the authors and/or other copyright owners and it is a condition of accessing publications that users recognise and abide by the legal requirements associated with these rights.

- Users may download and print one copy of any publication from the public portal for the purpose of private study or research.

- You may not further distribute the material or use it for any profit-making activity or commercial gain

- You may freely distribute the URL identifying the publication in the public portal 


\title{
Low Loss Mid-IR Transmission Bands using Silica Hollow-core Anisotropic Anti-resonant Fibers
}

\author{
Md. Selim Habib, Ole Bang, and Morten Bache \\ DTU Fotonik, Department of Photonics Engineering, Technical University of Denmark, DK-2800, Kgs. \\ Lyngby, Denmark
}

\begin{abstract}
In this paper, a node-free anisotropic hollow-core anti-resonant fiber has been proposed to give low transmission loss in the near-IR to mid-IR spectral regime. The proposed silica-based fiber design shows transmission loss below $10 \mathrm{~dB} / \mathrm{km}$ at $2.94 \mu \mathrm{m}$ with multiple low loss transmission bands. Transmission loss of $1 \mathrm{~dB} / \mathrm{m}$ up to $4 \mu \mathrm{m}$ is also predicted.
\end{abstract}

$\mathrm{R}$ ECENTLY hollow-core anti-resonant (HC-AR) fibers have proven an excellent optical medium in which light is transmitted inside a hollow-core and extensively studied over the past few years owing to their low loss transmission, wider transmission window, low dispersion and low fraction of power in the cladding [1]-[5]. Various HC-AR fiber designs have been proposed and implemented by several research groups in order to reduce the loss. HC-AR fibers with both circular AR tubes [1] and nested tubes inside the AR tubes [2], [4] have been investigated. The later designs confirm a significant loss reduction but increase design complexity.

In this work we propose a HC-AR fiber with anisotropic AR tubes, elongated along the fiber radial direction. The proposed design allows (a) an increased negative curvature in the core, (b) a node-free design, and (c) a larger distance from the core to the outer capillary. All these properties are essential to reduce the loss and could not be realized simultaneously in the previous designs.

Figure 1(a)-(b) shows the considered HC-AR fiber geometries in which both designs are optimized at $2.94 \mu \mathrm{m}$. Design (a) is a typical isotropic HC-AR fiber in which AR tubes are non-touching each other. Design (b) is the proposed structure based on anisotropic AR tubes; here an ellipse is considered which is squeezed in the azimuthal direction. We define ellipticity as $\eta=r_{\mathrm{y}} / r_{\mathrm{x}}$, where $r_{\mathrm{x}}$ and $r_{\mathrm{y}}$ are the radius of major and minor axis of the AR tubes respectively. We choose a core radius $R_{\mathrm{c}}=47 \mu \mathrm{m}$ as reported in [2], [4] and silica strut thickness $t=1.26 \mu \mathrm{m}$, which gives an anti-resonant first-order transmission window in the high-frequency mid-IR range (specifically around $\lambda=2.94 \mu \mathrm{m}$, the emission wavelength of Er:YAG lasers).

Figure 1(c) shows the loss spectrum of the two considered structures. In our calculations, the fraction of power in silica was calculated to estimate the effective material loss and then added to the leakage loss to obtain the total transmission loss. The material loss of silica was taken from [6]. The broken blue line shows the calculated leakage loss of a "typical" optimized HC-AR fiber in which the leakage loss and transmission loss are $\sim 35 \mathrm{~dB} / \mathrm{km}$ and $\sim 40 \mathrm{~dB} / \mathrm{km}$ respectively at $2.94 \mu \mathrm{m}$, which is limited by coupling to the voids in the cladding [2]. The broken red lines show the leakage loss of the proposed HC-AR fiber in which anisotropic AR tubes were used to reduce the loss. The leakage loss and transmission loss
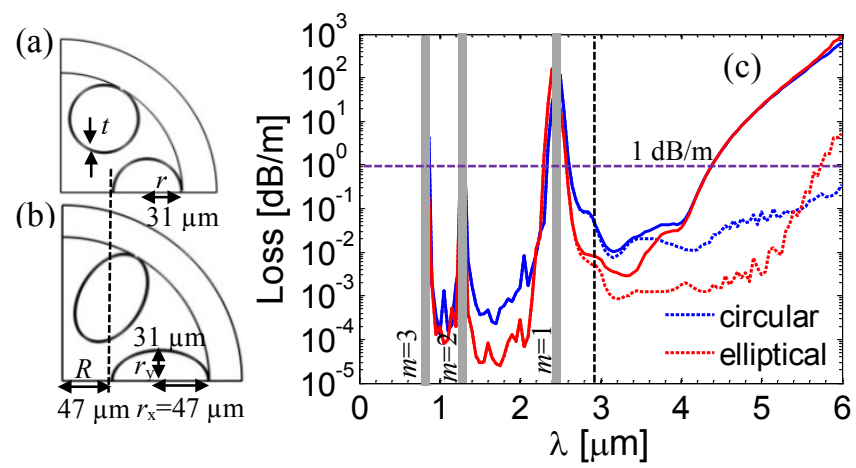

Fig. 1. (a-b) Geometry of the considered HC-AR fibers. The structural parameters shown in the figure are those that optimized the leakage loss at $2.94 \mu \mathrm{m}$. The figures are scaled to indicate their relative size. (c) Calculated transmission bands in the near-IR to mid-IR. The broken lines indicate leakage loss while solid lines show the transmission loss where the material loss of silica is included. All structures have the same core radius $R_{\mathrm{c}}=47 \mu \mathrm{m}$ and uniform silica strut thickness $t=1.26 \mu \mathrm{m}$.

are $\sim 5 \mathrm{~dB} / \mathrm{km}$ and $\sim 8 \mathrm{~dB} / \mathrm{km}$ respective at $2.94 \mu \mathrm{m}$ for the proposed structure. Thus, the anisotropic design has loss 5 times lower than the "typical" HC-AR fiber at $2.94 \mu \mathrm{m}$. Importantly we also found several low loss transmission bands in the whole near-IR to mid-IR region of $0.9-6.0 \mu \mathrm{m}$ for a fixed strut thickness of $1.26 \mu \mathrm{m}$. The proposed design shows better loss performance in the spectral regime $0.9-4.0 \mu \mathrm{m}$. Identical transmission loss performances were observed beyond $4 \mu \mathrm{m}$ for the 2 designs because the loss is dominated by material loss, despite the low power fraction in silica.

In conclusion, we have proposed a novel HC-AR fiber design which is generic, irrespective of glass composition and target wavelength. We believe that our proposed model proved to be an excellent means for the purpose of possible applications in mid-IR wavelength regime.

\section{REFERENCES}

[1] A. F. Kosolapov, A. D. Pryamikov, A. S. Biriukov, V. S. Shiryaev, M. S. Astapovich, G. E. Snopatin, V. G. Plotnichenko, M. F. Churbanov, and E. M. Dianov, "Demonstration of $\mathrm{CO}_{2}$-laser power delivery through chalcogenide-glass fiber with negative-curvature hollow core," Opt. Express, vol. 19, no. 25, pp. 25723-25728, Dec. 2011.

[2] W. Belardi and J. C. Knight, "Hollow antiresonant fibers with reduced attenuation," Opt. Lett., vol. 39, no. 7, pp. 1853-1856, Apr. 2014.

[3] F. Poletti, "Nested antiresonant nodeless hollow core fiber," Opt. Express, vol. 22, no. 20, pp. 23807-23828, Sep. 2014.

[4] M. S. Habib, O. Bang, and M. Bache, "Low-loss hollow-core silica fibers with adjacent nested anti-resonant tubes," Opt. Express, vol. 23, no. 13, pp. 17394-17406, 2015.

[5] M. S. Habib, O. Bang, and M. Bache, "Low-loss single-mode hollowcore fiber with anisotropic anti-resonant elements," Opt. Express, vol. 24, no. 8, p. 8429, 2016.

[6] O. Humbach, H. Fabian, U. Grzesik, U. Haken, and W. Heitmann, "Analysis of $\mathrm{OH}$ absorption bands in synthetic silica," J. Non. Cryst. Solids, vol. 203, pp. 19-26, Aug. 1996. 